\title{
Influences of powder characteristics and recoating conditions on surface morphology of powder bed in metal additive manufacturing
}

\author{
Kenya Yuasa ${ }^{1} \cdot$ Masaharu Tagami $^{2} \cdot$ Makiko Yonehara $^{2} \cdot$ Toshi-Taka Ikeshoji $^{2} \cdot$ Koki Takeshita $^{3} \cdot$ Hiroshi Aoki $^{3} \cdot$ \\ Hideki Kyogoku ${ }^{2}$
}

Received: 7 January 2021 / Accepted: 26 May 2021 / Published online: 12 June 2021

(C) The Author(s) 2021

\begin{abstract}
Metal additive manufacturing technology requires a real-time monitoring and feedback control system to assure the quality of the final products. In particular, it is essential to reveal the phenomena of recoating and melting-solidification processes in laser powder bed fusion using a real-time monitoring system because they influence strongly the occurrence of defects. This study was conducted to elucidate the correlation among the powder characteristics, recoating conditions, and surface morphology of a powder bed in the recoating process to determine the relationship between the surface morphology of the powder bed and the final product quality. To this end, a surface morphology measurement system composed of a powder recoating test bench and a layer surface morphology measurement apparatus was first designed and fabricated. Then, it was used to quantify the surface morphology of the powder bed. Specifically, the influences of the different powder characteristics and the recoating parameters of the powder supply ratio and recoating speed on the surface morphology of the powder bed were investigated using various powders of Al-10Si-0.4Mg (AlSi10Mg) alloy and Inconel 718 (IN718) alloy. The surface morphology of the powder bed was measured as the value of $2 \sigma$ at a resolution of $30 \mu \mathrm{m}$ in height. It was found that the angle of repose and the basic flow energy of the bulk powder are promising parameters for evaluating the surface morphology. The surface morphology was significantly affected by the powder characteristics and recoating speed. The value of $2 \sigma$ for the AlSi10Mg powder increased rapidly over a recoating speed of $50 \mathrm{~mm} / \mathrm{s}$ for all powders. The value of $2 \sigma$ for the irregularly shaped AlSi10Mg powder was approximately 19 $\mu \mathrm{m}$, and the $2 \sigma$ values for the other powders were approximately $17 \mu \mathrm{m}$ at a recoating speed of $15 \mathrm{~mm} / \mathrm{s}$. However, at a recoating speed greater than $300 \mathrm{~mm} / \mathrm{s}$, the irregularly shaped powder exhibited better surface morphology than did the spherical powder. The recycling process deteriorated the flowability of the new powder. However, the surface morphology of the spherical recycled powder was similar to that of the spherical powder. Consequently, the correlation among the powder characteristics, recoating conditions, and surface morphology of the powder bed was revealed by employing the surface morphology measurement system. Quantification of the surface morphology of the powder bed using the monitoring system facilitates control of the recoating process to prevent the occurrence of defects.
\end{abstract}

Keywords Additive manufacturing $\cdot$ Measurement methodology $\cdot$ Powder characteristics $\cdot$ Powder bed fusion $\cdot$ Monitoring $\cdot$ Surface morphology

Hideki Kyogoku

kyogoku@hiro.kindai.ac.jp

1 Graduate School of Systems Engineering, Kindai University, 1 Takaya-Umenobe, Higashihiroshima, Hiroshima 739-2116, Japan

2 Fundamental Technology for Next Generation Research Institute, Kindai University, 1 Takaya-Umenob, Higashihiroshima, Hiroshima 739-2116, Japan

3 Nikon Co., 471 Nagaodai-cho, Sakae-ku, Yokohama, Kanagawa 244-8533, Japan

\section{Introduction}

Additive manufacturing (AM) technology has been utilized as a promising material process because it enables the integrated manufacturing of complexly shaped products with the addition of new functions. In particular, powder bed fusion-laser beam (PBF-LB) technology, which is a type of AM, has been utilized in industrial fields such as the aerospace, medical, and energy fields. These fields require the stable manufacturing of high-quality products. Therefore, the 
development of a real-time monitoring and feedback system is essential for the stable manufacturing of products without the occurrence of defects $[1,2]$.

The assurance of the quality of the final products manufactured using the PBF-LB process requires the control of various process parameters in the powder characteristics, powder recoating process, and building process applying laser radiation. Mani et al. [2] reviewed the measurement science requirements that are critical in real-time AM process control, as well as the correlations among the process parameters, process signatures, and product quality. Moges et al. [3] classified the PBF-LB process into five physical phenomena to improve model inaccuracy and parameter uncertainty in PBF-LB models and simulations. Regarding the parameters of the powder recoating, they indicated that the powder size and shape, particle size distribution (PSD), layer thickness, and recoater shape are essential. Among these parameters, the recoating speed correlates with the surface morphology and powder layer density of the powder bed $[4,5]$, and these parameters on the powder bed significantly affect the formation of the melt pool [6-8]. Moreover, Vock et al. [9] reviewed the influence of the powder properties on the part properties considering the powder properties and bulk powder behavior during recoating. Although the investigation of the relationship between the powder properties and the powder behavior during recoating is important, there are few reports on such experiments [10], excepting those that consider numerical simulations [10-18]. In addition, the various process parameters of the powder properties, surface morphology of the powder bed, and laser radiation conditions are essentially correlated with the final product properties.

The particle size, shape, and PSD among the powder characteristics affect the flowability of the bulk powder, as well as the flowability and recoating conditions. The recoating speed and blade shape have a considerable impact on the surface morphology of the powder bed in the PBF process. The flow rate measured by the Hall flow test is widely employed as a parameter of flowability. However, it was reported that the Hall flow test is not best suited for AM powder characterization [9, 19]. Recently, dynamic parameters measured by using a powder rheometer have been employed to assess bulk powder characteristics, and informative results regarding AM have been reported [9] [20-22]. The rheological parameters of the stability index (SI), specific energy (SE), and conditioned bulk density (CBD) obtained by using an FT4 powder rheometer correlate well with the performance during powder recoating [9]. In addition, the powder characteristics for AM were investigated using a revolution powder analyzer (Mercury Scientific Inc.) [19], [23, 24]. Snow et al. [23] revealed that the avalanche angle showed poor correlation with the spreadability of the powder in PBF.

The powder layer density, layer thickness, and surface morphology of the powder bed influence the melting and solidification behavior of the powder layer in the PBF-LB process. Several studies [25-27] have been conducted to investigate the relationship between the powder characteristics and powder bed density (PBD). These studies concluded that the PBD is approximately $60 \%$.

Numerous studies have been conducted to investigate the recoating behavior using the discrete element method (DEM) in PBF [11-18]. The relationship among the surface roughness, the recoating speed, and the powder size distribution has been investigated via DEM simulation [13-16]. Dasai et al. [17] created a process map between the recoating speed and surface roughness derived from physics model-based machine learning.

In addition, the melting and solidification phenomena by laser radiation, as well as the cause of the occurrence of defects related to laser radiation, have been reported [28-34]. The influences of process parameters on the accuracy, surface roughness, and mechanical properties of the products $[35,36]$ have also been evaluated. Mindt et al. [37] investigated the formation of defects in a powder bed obtained via recoating and defects in the product obtained by laser radiation. Although the influence of the powder bed quality on the melt-pool behavior has been reported [38, 39], only a limited number of studies have been conducted regarding the influence of the surface morphology of the powder bed on the final product quality.

Recently, the influence of powder characteristics on the powder bed quality during the recoating process has been investigated experimentally [40]. Snow et al. [23] reported on the effects of the powder characteristics, recoating speed, and avalanche angle on the spreadability of the powder using the spreadability testing rig; however, they did not investigate the effects of these parameters on the surface morphology. Sun et al. [41] evaluated the surface morphology of powder beds using a digital camera, but could not provide a quantitative analysis.

Therefore, it has been determined that the surface morphology of the powder bed seriously affects the density, surface roughness, and mechanical properties of the final products. However, the influences of the powder characteristics and recoating speed on the surface morphology of a powder bed have not been adequately investigated and quantified.

The aim of this study is to elucidate the correlation between the powder characteristics and recoating behavior during the PBF process using a surface morphology measurement system to reveal the relationship between the surface morphology of the powder bed and the final product quality. In this study, a surface morphology measurement system composed of a powder recoating test bench and a layer surface morphology measurement apparatus is first designed and fabricated. Then, the surface morphology of the powder bed is quantified using this system, and the correlations among the different powder characteristics, recoating parameters of the powder supply ratio and recoating speed, and surface morphology of the powder bed are investigated. 


\section{Development of surface morphology measurement system}

\subsection{Powder recoating test bench}

In this study, a surface morphology measurement system was designed and fabricated. The system is composed of a powder recoating test bench and a layer surface morphology measurement apparatus, as demonstrated in Fig. 1a. A powder recoating test bench equipped with a powder supply unit, build unit, and recoater with a stainless steel blade was designed, and the recoating speed was controlled via a machine controller. The layer height was manually adjusted using micrometer calipers. The main specifications of the test bench are as follows:

- $\quad$ Recoating speed: $\max .500 \mathrm{~mm} / \mathrm{s}$

- Build volume: $150 \mathrm{~mm} \times 150 \mathrm{~mm} \times 150 \mathrm{~mm}$

- Blade material: stainless steel

- Resolution in height: $30 \mu \mathrm{m}$

\subsection{Layer surface morphology measurement system and measurement methodology}

The measurement methods of surface morphology of powder bed have been proposed. Depond et al. [42] measured the surface roughness of powder bed by the arithmetrical mean height, $S_{\mathrm{a}}$, which is one of the areal surface-texture parameters, obtained using low coherence scanning interferometry technique. Additionally, the fringe projection technique based on triangulation method has been frequently applied to mainly measure the surface roughness of fused surface in the powder bed [17], [43-45]. Desai et al. [17] proposed to measure the surface roughness of powder bed using the surface roughness parameter, $R_{\mathrm{q}}$, and created the process maps between spreading speed and spreadability parameters via machine learning. In this study, the light-patterned (fringe projection) technique was applied to measure the surface morphology of powder bed as exhibited in Fig. $1 \mathrm{~b}$.

A layer surface morphology measurement system was developed to quantify the surface morphology of the examined powder bed and the surface of the built parts using the lightpatterned projecting method, as demonstrated in Fig. 2. The point group data of the three-dimensional surface are generated by the triangulation method using the displacement of the projection patterns of the parallel stripes. The surface morphology of the powder bed was quantified using the standard deviation, $\sigma$, (Eq. (1)) as follows.

(1) The point group data of the three-dimensional surface of the measurement area of $80 \times 80 \mathrm{~mm}^{2}$ (Fig. 2b) on a build plate were obtained by the layer surface morphology measurement system.

(2) The best-fit plane obtained by the least squares method was defined using the point group data.

(3) The standard deviation, $\sigma$, of the $z$-position values of the surface point group data was calculated on the basis of the best-fit plane. Then, to eliminate noise, the point

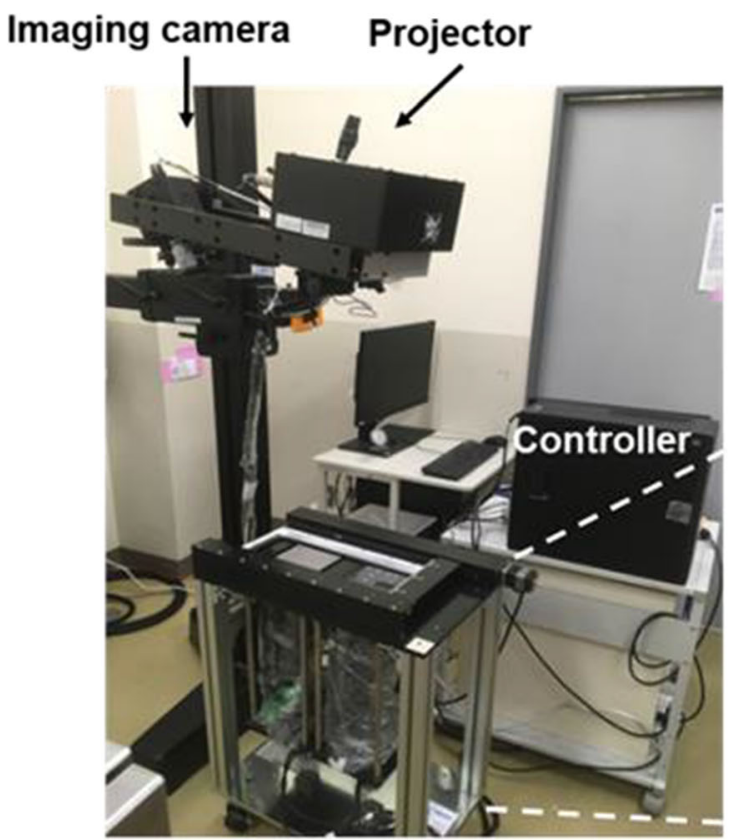

(a)

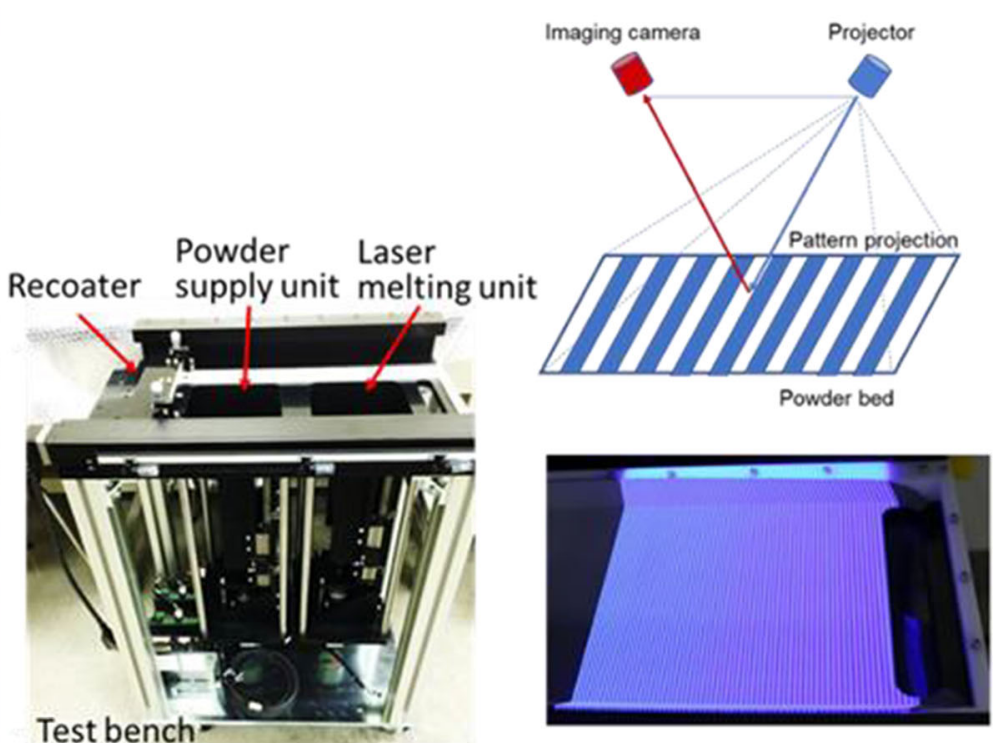

(b)

Fig. 1 a Surface morphology measurement system and $\mathbf{b}$ schematic of light-patterned projection setup 


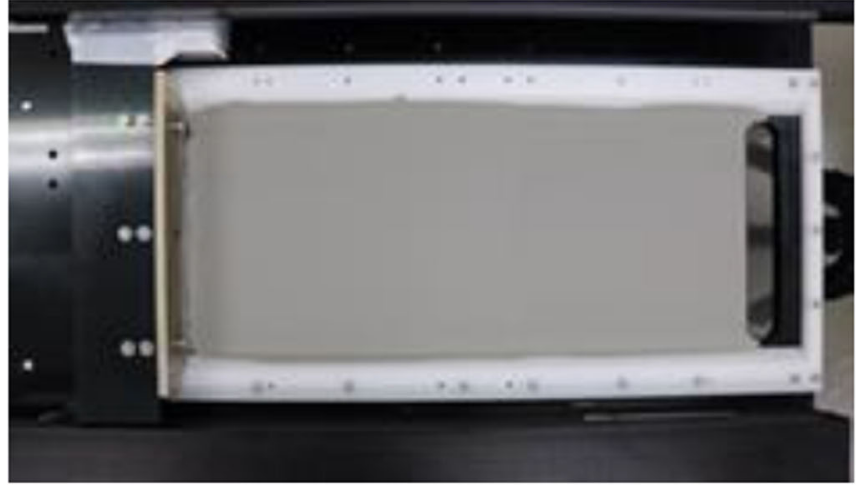

(a)

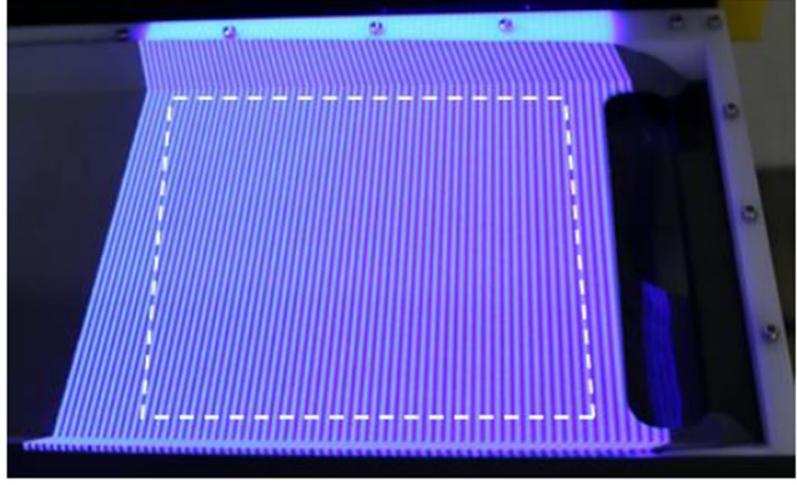

(b)

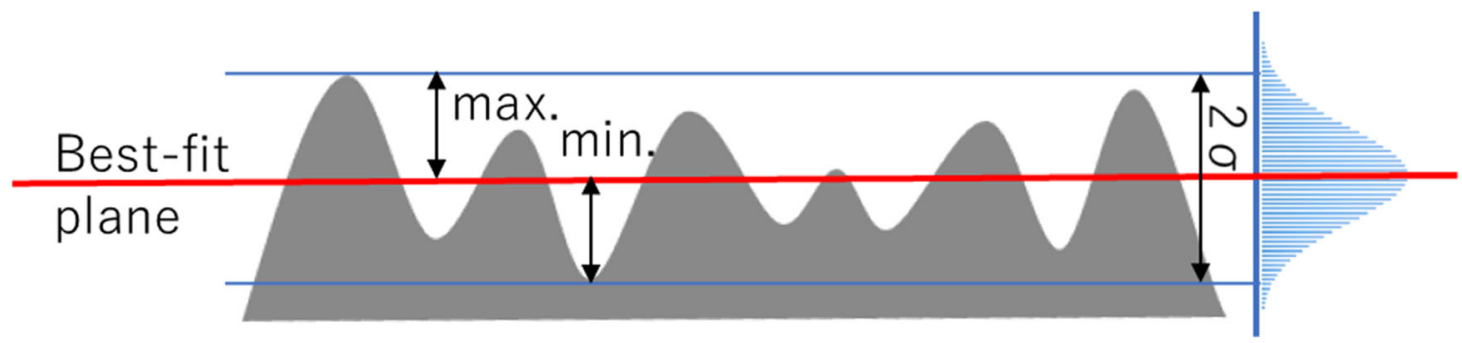

(c)

Fig. 2 Measurement of the surface morphology of the powder bed. a Powder bed (before pattern projection). b Pattern projection. $\mathbf{c}$ Definition of $2 \sigma$

group data in the range of $2 \sigma(95 \%)$ were used for the evaluation of the surface morphology of the powder bed. The value of $2 \sigma$ implies $2 S_{\mathrm{q}}$ ( $S_{\mathrm{q}}$ : root mean square height), which is one of the areal surface-texture parameters.

$$
\sigma=\sqrt{\frac{1}{n} \sum_{i=1}^{n}\left(z_{i}-\bar{z}\right)^{2}} \approx S_{q}
$$

where $n$ is the number of the surface point group data, $z_{\mathrm{i}}$ is the height from the best-fit plane, and $\bar{z}$ is the average of the $z$ position values of the surface point group data.

This measurement system has the capability of measuring the surface morphology of a powder bed at a resolution of $30 \mu \mathrm{m}$ in height.

\section{Experimental procedures}

\subsection{Feedstock characteristics}

The Al-10Si-0.4Mg (AlSi10Mg) alloy and Inconel 718 (IN718) superalloy were selected in this study because the former and the latter are applied to products in various industry fields, such as light-weight parts and heat exchanger, and to products in aerospace and energy industry fields, such as turbine blades and aero-engines, respectively. Three types of
AlSi10Mg and IN718 powders, which have various particle shapes and PSDs, were employed in this study. The powder characteristics of the three types of AlSi10Mg and IN718 powders are summarized in Table 1. Scanning electron microscopy (SEM) images of these powders are shown in Fig. 3. The PSDs of these powders are shown in Fig. 4. The powder characteristics of these powders were measured using a laser diffraction particle size analyzer, an automated particle shape analysis and size measurement system (Malvern Morphologi G3), a Hall flowmeter, and a powder rheometer (Freeman Technology FT4). Considering the AlSi10Mg powders, the Al-A powder is gas-atomized and irregularly shaped with a narrow PSD. The Al-B powder is centrifugal-atomized, spherically shaped with a wide PSD. The Al-C powder is gas-atomized, round-shaped with two peaks of PSD, indicating that it is a bimodal powder. The circularity of the Al-B powder was the highest. With regard to the IN718 powders, the PSD of IN$B$ is narrower than that of IN-C, and that of IN-C is between them. These powders were dried in an oven at $110{ }^{\circ} \mathrm{C}$ for 30 min before the recovery test to maintain a constant bulk powder humidity.

The powder size, shape, and PSD among the powder characteristics affect the flowability, which has been identified as a bulk powder property [9]. Moreover, the flowability and the recoating conditions have a significant impact on the powder bed characteristics such as the PBD and surface morphology [3-5], [9]. In general, it is known that a spherical shape, large 
Table 1 Powder characteristics of the three types of AlSi10Mg and IN718 powders

\begin{tabular}{|c|c|c|c|c|c|c|c|}
\hline \multicolumn{2}{|l|}{ Powder } & \multirow{2}{*}{$\frac{\text { Al-A }}{\text { AlSi10Mg }}$} & \multirow[t]{2}{*}{ Al-B } & \multirow[t]{2}{*}{$\mathrm{Al}-\mathrm{C}$} & \multirow{2}{*}{$\frac{\mathrm{IN}-\mathrm{A}}{\mathrm{IN718}}$} & \multirow[t]{2}{*}{ IN-B } & \multirow[t]{2}{*}{ IN-C } \\
\hline Material & & & & & & & \\
\hline Particle shape & & Irregular & Spherical & Round & Round & Round & Round \\
\hline \multirow[t]{3}{*}{ Size } & $\mathrm{D} 10[\mu \mathrm{m}]$ & 23.18 & 25.08 & 3.43 & 20.29 & 26.64 & 17.29 \\
\hline & $\mathrm{D} 50[\mu \mathrm{m}]$ & 34.51 & 36.57 & 9.05 & 38.92 & 39.88 & 29.61 \\
\hline & $\mathrm{D} 90[\mu \mathrm{m}]$ & 49.38 & 57.9 & 34.59 & 71.29 & 61.32 & 51.08 \\
\hline \multirow[t]{2}{*}{ Hall flow test } & Orifice $\varphi 5.0 \mathrm{~mm}[\mathrm{~s}]$ & 12.4 & 8.1 & 14.3 & 2.58 & 2.4 & 3.32 \\
\hline & Orifice $\varphi 2.5 \mathrm{~mm}[\mathrm{~s}]$ & 71.7 & 52.5 & 81 & 12.17 & 12.94 & 15.48 \\
\hline \multicolumn{2}{|c|}{ Angle of repose $\left[^{\circ}\right]$} & 33 & 26 & 31 & 28 & 28 & 28 \\
\hline \multicolumn{2}{|l|}{ Carr’s index } & 78 & 87 & 84 & - & - & - \\
\hline \multirow[t]{5}{*}{ FT4 } & $\mathrm{BFE}[\mathrm{mJ}]$ & 408.9 & 256.68 & 374.45 & 775.59 & 594.96 & 857.04 \\
\hline & $\mathrm{SE}[\mathrm{mJ} / \mathrm{g}]$ & 4.19 & 2.79 & 3.66 & 2.81 & 2.15 & 3.12 \\
\hline & SI & 1.02 & 1.02 & 1.05 & 1.06 & 0.96 & 1.00 \\
\hline & FRI & 1.21 & 1.22 & 1.22 & 1.12 & 1.00 & 1.18 \\
\hline & $\mathrm{FF}$ & 22 & 12 & 12 & 7.7 & 7.63 & 8.24 \\
\hline
\end{tabular}

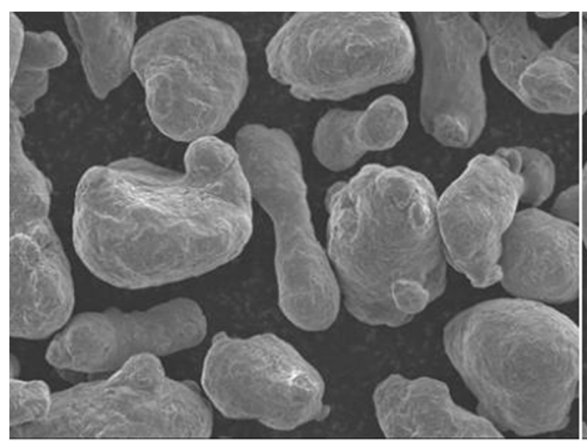

(a) Al-A

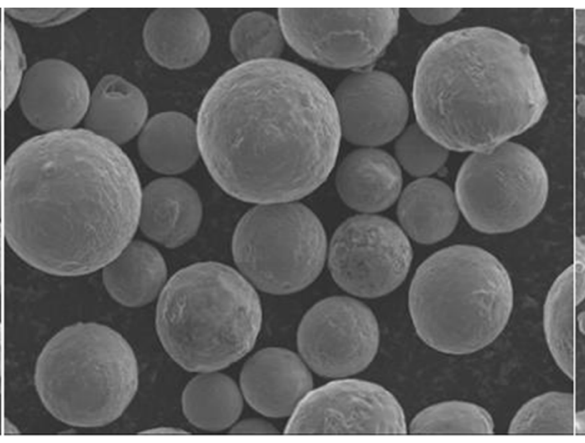

(b) Al-B

(A)

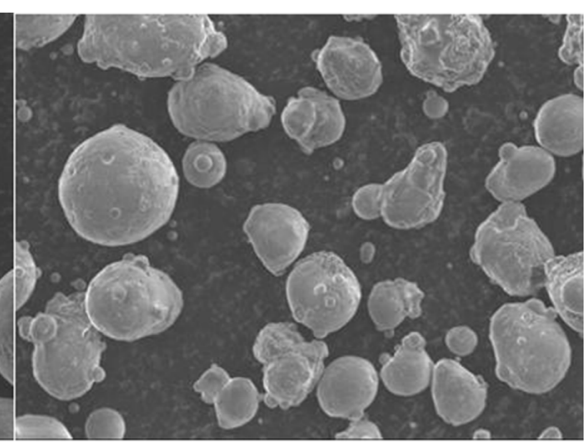

(c) Al-C

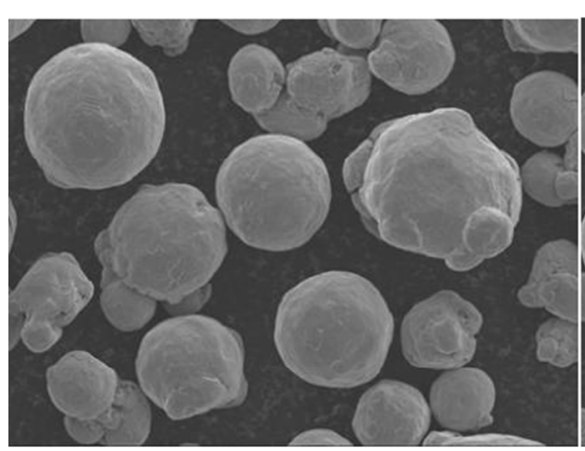

(a) IN-A

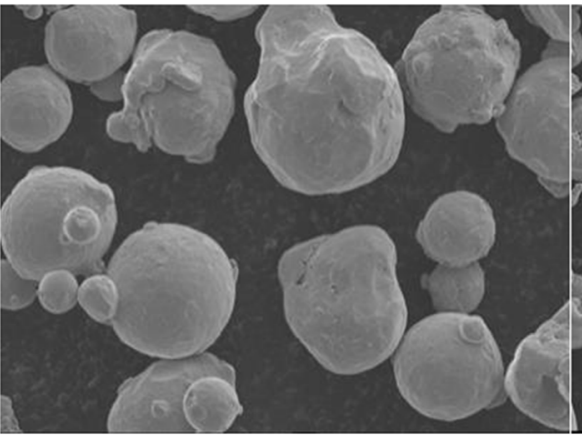

(b) IN-B

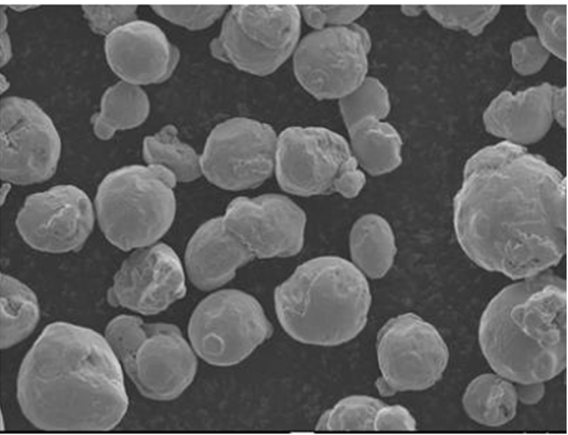

(c) IN-C

(B)

Fig. 3 SEM images of the three types of AlSi10Mg and IN718 powders. A AlSi10Mg powders: (a) Al-A, (b) Al-B, (c) Al-C. B IN718 powders: (a) INA, (b) IN-B, (c) IN-C 


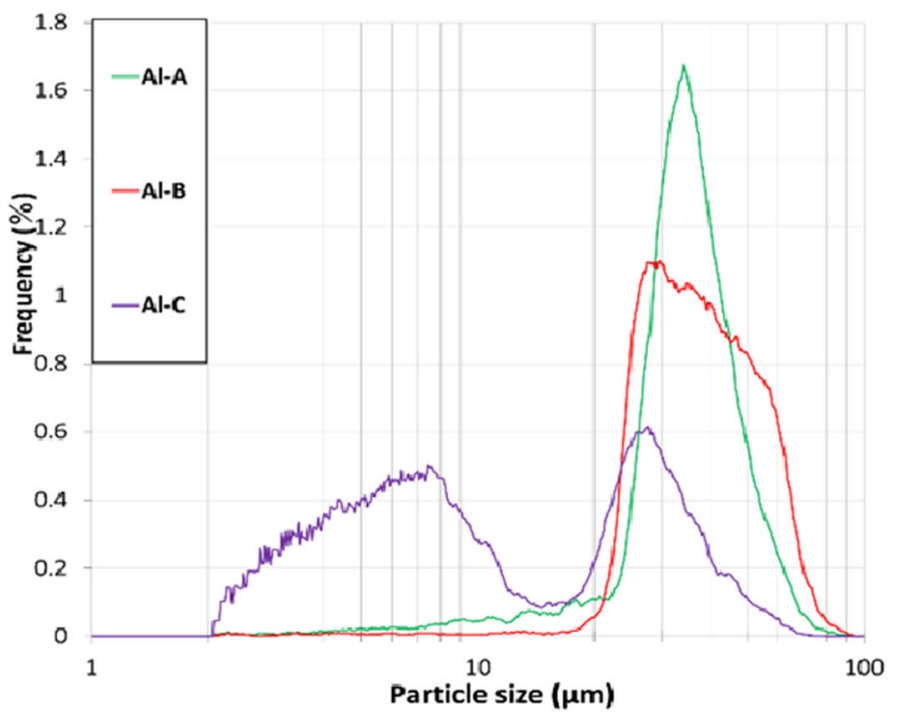

(a)

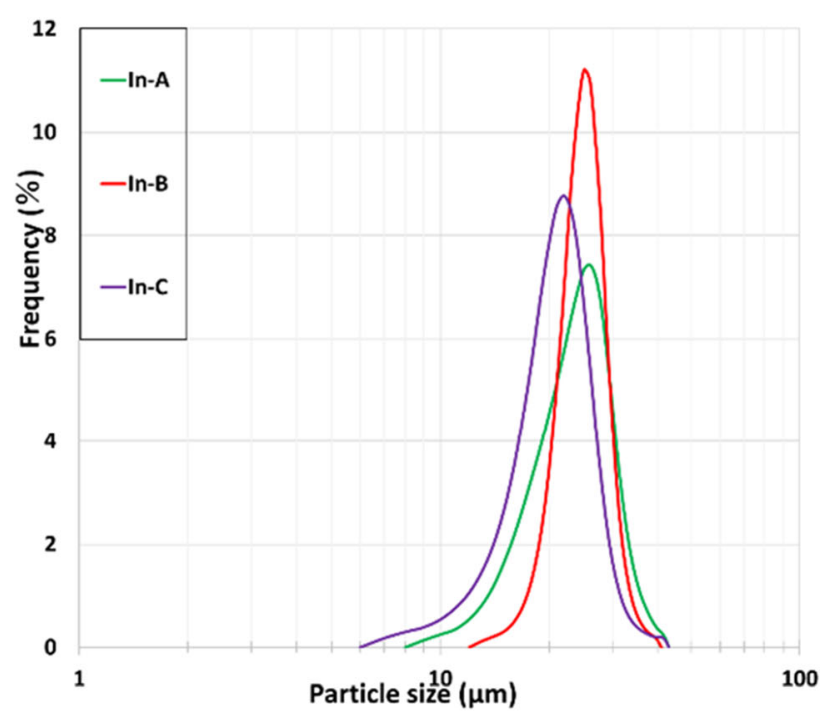

(b)

Fig. 4 Particle size distributions of the three types of AlSi10Mg and IN718 powders. a AlSi10Mg powders. b IN718 powders

size, and narrow PSD powder demonstrates better flowability. The flow rate $(\mathrm{s} / 50 \mathrm{~g})$ using a Hall flowmeter funnel and the angle of repose (AOR) are frequently applied to examine the flowability of a bulk powder. Regarding the IN718 powders, all powders showed good flowability. In contrast, regarding the AlSi10Mg powders, the flow rates of Al-A, Al-B, and AlC obtained using a $\varphi 5$-mm orifice were $12.4 \mathrm{~s}, 8.1 \mathrm{~s}$, and 14.3 $\mathrm{s}$, respectively. Therefore, these powders exhibited good flowability, and the flowability of Al-B was the highest among these powders because this powder is spherical and large in size. Spierings et al. [19] concluded that the Hall flow test is not the best suited test for AM powders. Geldart et al. [46] reported that the AOR can be applied to characterize a wide range of powders to determine their flowability. Therefore, although the flow rate and AOR of these powders could be applied as parameters of the flowability, the appropriate flowability in the PBF is considered to depend strongly on the mechanism of the PBF machine (such as the mechanism of the powder supply and recoater blade), as stated by Spierings et al. [19] and Jacob et al. [40].

In addition, the powder rheology was measured using the Freeman Technology FT4 Powder Rheometer. The influence of the flowability on the surface morphology of the powder bed was investigated to reveal the correlation between the surface morphology of the powder bed and the bulk powder characteristics such as the basic flowability energy (BFE), SE, SI, flow rate index (FRI), and flow function (FF).

Concerning the powder rheological parameters measured using the FT4 powder rheometer, the BFE of the IN718 powders is considerably higher than that of the AlSi10Mg powder, whereas the SE of the IN718 powders is lower. Regarding the IN718 powders, the BFE and SE of IN-B are the lowest because it possesses the narrowest PSD. Regarding the AlSi10Mg powders, the $\mathrm{BFE}$ and $\mathrm{SE}$ values increase in the order of $\mathrm{Al}-\mathrm{B}<\mathrm{Al}-$ $\mathrm{C}<\mathrm{Al}-\mathrm{A}$. The flowability of Al-B is the best because the flow energy of this powder is the lowest. This result corresponds to those of the flow rate and AOR. The SI of Al-C is slightly higher than that of the other powders. This may be because the apparent density of Al-C is high due to it being a bimodal powder [47]. Because the FRI is approximately similar for all powders, these powders are insusceptible to flow rate changes. All powders show good flowability, as noted previously [48], because the FF of any AlSi10Mg powder is higher than 10 [49]. However, the FF is considered to be unsuitable for identifying the flowability because the FF of Al-A is substantially higher than that of the other powders.

\subsection{Experimental methods}

First, the recoating test was performed at a recoating speed of 15-200 mm/s. The recoating speed of a commercial machine is generally less than $200 \mathrm{~mm} / \mathrm{s}$. The effect of the amount of powder being supplied on the surface morphology was examined because the amount of powder being supplied affects the surface morphology of the powder bed. The powder supply ratio (PSR) was defined as the ratio of the increase in height of the powder supply unit to the decrease in height of the build unit. The PSR was varied between 1.5 and 3.0. The recoating test was conducted at a layer thickness of $100 \mu \mathrm{m}$ after achieving a pre-recoating of $100 \mu \mathrm{m}$ in thickness. The surface morphology of the powder bed was measured thrice as the value of $2 \sigma$ using the layer surface morphology measurement system. 


\section{Results and discussions}

\subsection{Influence of process parameters on the surface morphology of the powder bed}

To assure the quality of the final products manufactured by the PBF-LB process, the control of various process parameters is required, including the powder characteristics, powder recoating process, and building process via laser radiation, as shown in Fig. 5. In particular, it is essential to determine the state of the powder layer characteristics because the surface morphology or uniformity of the powder bed derived from the powder characteristics has a large impact on the formation of the melt pool. The deterioration of the powder bed properties leads to the occurrence of defects such as lack of fusion and pores, as well as the lowering of the surface roughness and mechanical properties of the final products $[2,3,7]$. Qiu et al. [29] revealed that an increase in the layer thickness leads to an increase in the porosity of the as-built parts. Regarding the powder layer characteristics, the powder layer density in particular has been investigated by numerical simulations [14] and experimentation [24, 25, 40]. However, the surface morphology of the powder bed strongly influences the melting phenomena of the powder bed during laser radiation, and the measurement of the surface morphology of the powder bed has been rarely performed, except for investigation via DEM simulation $[11-13,16]$.

It is impossible to use only the PBD to determine the state of the entire area of the powder bed. Moreover, the surface morphology depends not only on the powder characteristics, but also on the recoating parameters including the recoating speed and recoating mechanism in the PBF machine, such as the recoating blade. As indicated by Vock et al. [9] and Jacob et al. [40], the investigation of various parameters on the surface morphology of a powder bed using a developed powder layer device results in improved quality assurance of the final products and provides basic data for improving or designing the PBF machine. Therefore, the influences of the powder characteristics and recoating speed on the surface morphology of the powder bed were investigated by employing a surface morphology measurement system.

\subsection{Influence of the bulk powder characteristics on the surface morphology of the powder bed}

The influence of the powder supply ratio (PSR) on the surface morphology of the powder bed was investigated to examine whether the powder supply was sufficient on the base plate. The PSR was varied between 1.5 and 3.0. At a PSR of 1.0, the uniform powder layer could not form because of the lack of supplied powder. At a PSR of more than 1.5, a uniform powder layer could be formed. Therefore, the recoating test was conducted at a PSR of more than 1.5.

The influence of the recoating speed on the surface morphology of the powder bed was investigated. The variations in the surface morphology of the various AlSi10Mg powder beds as a function of the recoating speed at a PSR of 2.0 are shown in Fig. 6. The red area indicates a convex part, and the blue area indicates a concave part. The surface morphology deteriorated as the recoating speed was increased. In particular, the Al-A powder is remarkably affected by the recoating speed. On the other hand, the surface morphologies of the Al$\mathrm{B}$ and Al-C powders are scarcely affected by the recoating speed. The variation of the value of $2 \sigma$ of the powder bed for various AlSi10Mg powder beds as a function of recoating speed is shown in Fig. 7. The value of $2 \sigma$ for Al-A is higher than that for the others. The value of $2 \sigma$ for Al-A is approximately $19 \mu \mathrm{m}$ at a recoating speed of $15 \mathrm{~mm} / \mathrm{s}$, and the values
Fig. 5 LB-PBF process and related process parameters

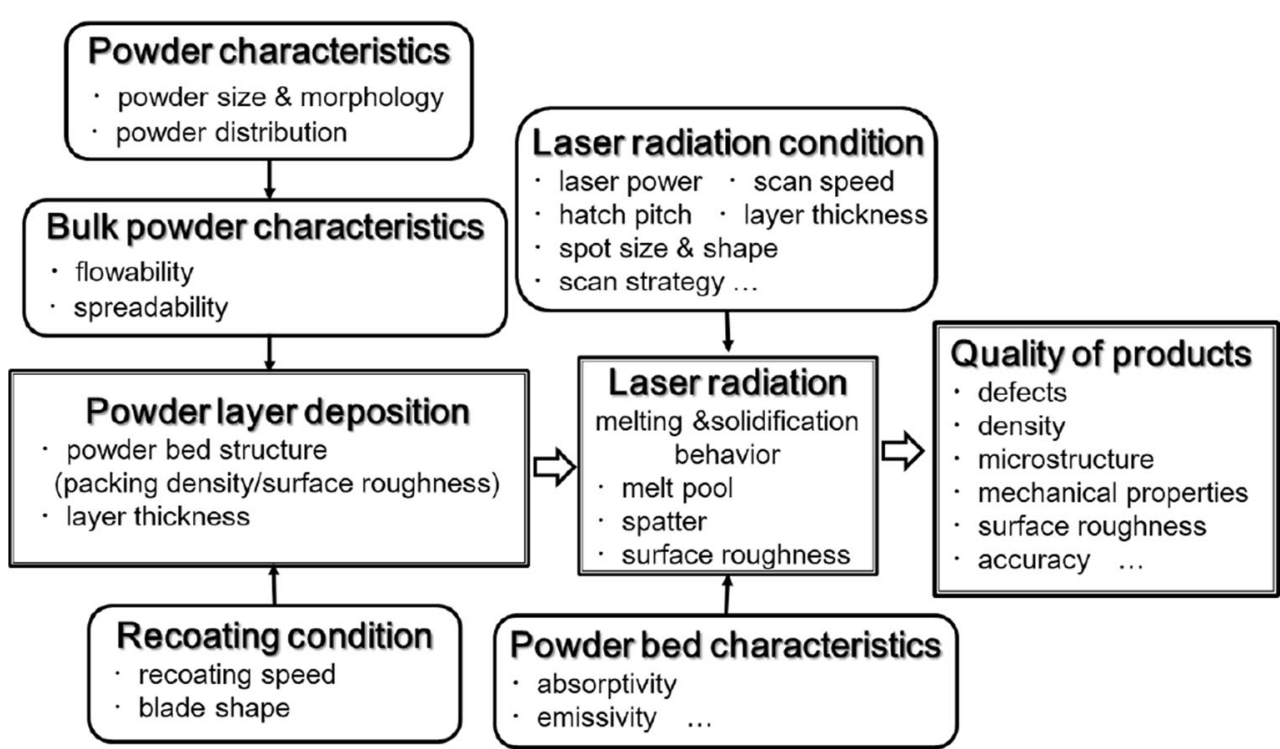


Fig. 6 Variations in the surface morphology of the various AlSi10Mg powder beds as a function of recoating speed

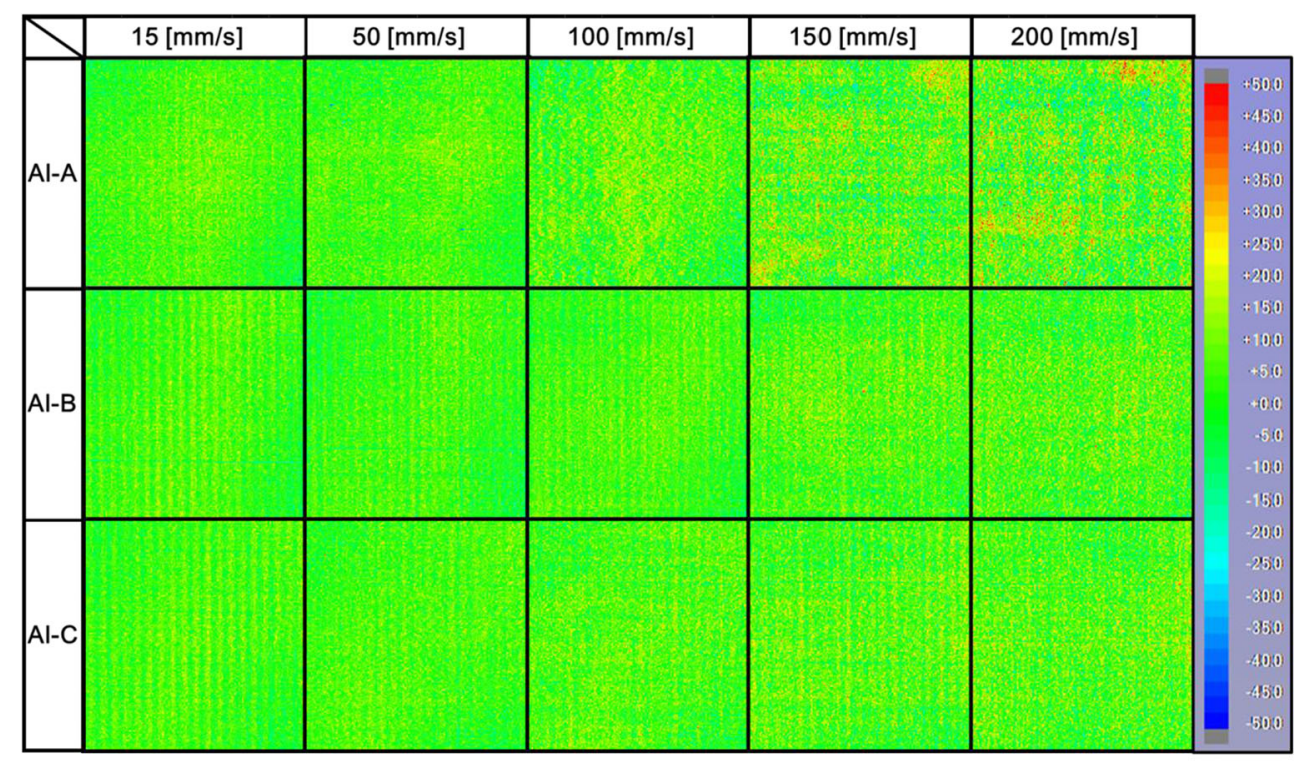

Recoating Direction of $2 \sigma$ for Al-B and Al-C are both approximately $17 \mu \mathrm{m}$. The value of $2 \sigma$ increases gradually over a recoating speed of 50 $\mathrm{mm} / \mathrm{s}$ for all powders. The value of $2 \sigma$ for Al-A is greater than $30 \mu \mathrm{m}$ at $200 \mathrm{~mm} / \mathrm{s}$, whereas those for Al-B and Al-C are approximately 23 and $24 \mu \mathrm{m}$, respectively. The value of $2 \sigma$ for Al-B is slightly lower than that for Al-C. Therefore, the surface morphology of the powder bed recoated using the Al$B$ powder showed the highest uniformity. Meier et al. [16] suggested that a reduced flowability might improve the powder bed quality at high recoating speeds as a result of their DEM simulation. In this study, however, the reduced

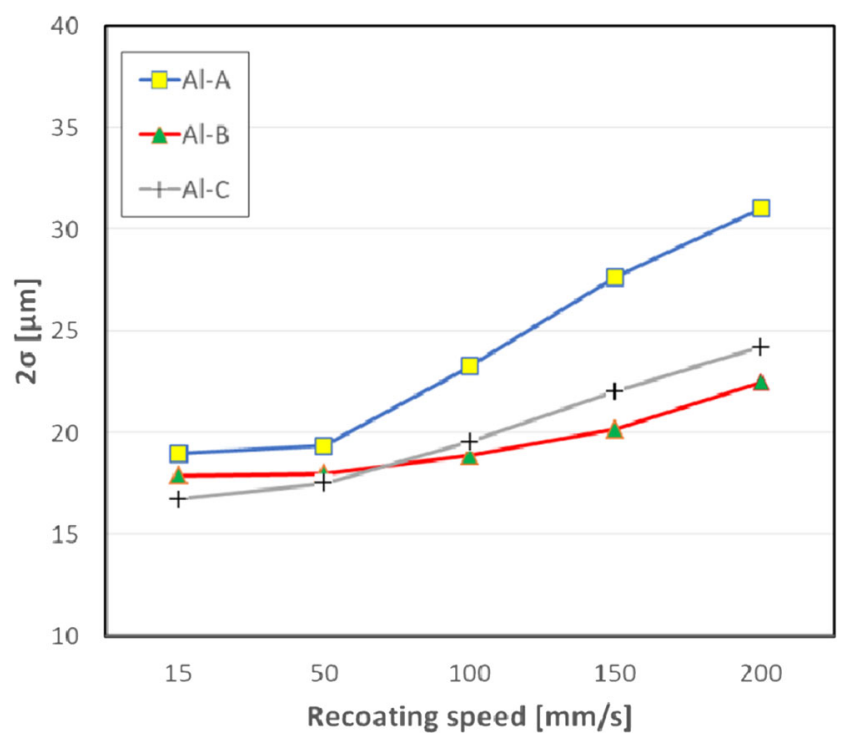

Fig. 7 Variation of $2 \sigma$ for various AlSi10Mg powder beds as a function of recoating speed flowability powders of the non-spherical Al-A powder deteriorated the quality of the surface morphology, while the bimodal Al-C powder having the lowest flowability hardly changed with an increase in recoating speed. This may be because, as the bimodal Al-C powder is composed of fine powder and coarse powder, fine powder filled the space between coarse powder. Chen et al. [50] reported that the surface roughness $\left(R_{\mathrm{a}}\right)$ measured by a laser profiler decreased with increasing recoating speed of a rolling-type recoater. The surface roughness is similar to our result.

In addition, the value of $2 \sigma$ for the bimodal Al-C powder is similar to that for the single-mode Al-B powder up to a recoating speed of $50 \mathrm{~mm} / \mathrm{s}$, but it is higher than that for Al-B at a recoating speed of greater than $100 \mathrm{~mm} / \mathrm{s}$, as shown in Fig. 6 and Fig. 7. Jacob et al. [40] investigated the variations in the powder characteristics of a powder with a wide PSD and a powder with a high proportion of finer particles during recoating. As a result, the former powder leads to a higher PBD than the latter owing to particle segregation behavior during recoating by the front stress-free turning powder wedge behavior [24]. Therefore, the difference in surface morphology between Al-B and Al-C powders may be due to the variation in the PSD of the Al-C powder with a high proportion of finer particles. However, the variation of the PBD along the direction of the recoater movement is not clearly observed in Fig. 6. This might be because the layer thickness of the powder layer in this study is thicker than that used by Jacob et al. [40].

The influence of the powder characteristics on the surface morphology of the powder bed was investigated using three types of AlSi10Mg powders. The powder characteristics of the three AlSil0Mg powders differ in terms of their flow rate, 
AOR, BEF or SE, and Carr's index, as shown in Table 1. Therefore, the relationship between these bulk powder characteristics and the value of $2 \sigma$ was examined, as shown in Fig. 8 . The value of $2 \sigma$ shows a tendency to increase and then decrease with an increasing flow rate. Considering the different types of powders, the value of $2 \sigma$ for Al-A is higher than those of the others. This result suggests that it may be difficult to evaluate the surface morphology using only the flow rate. This may be because the Hall flow test measures static behavior only by the gravity, and the recoating process is a dynamic behavior achieved by moving a recoater blade. Although the value of $2 \sigma$ increases gradually with an increasing AOR, the tendency differs from that of the flow rate. Therefore, the change in the value of $2 \sigma$ with the AOR is independent of

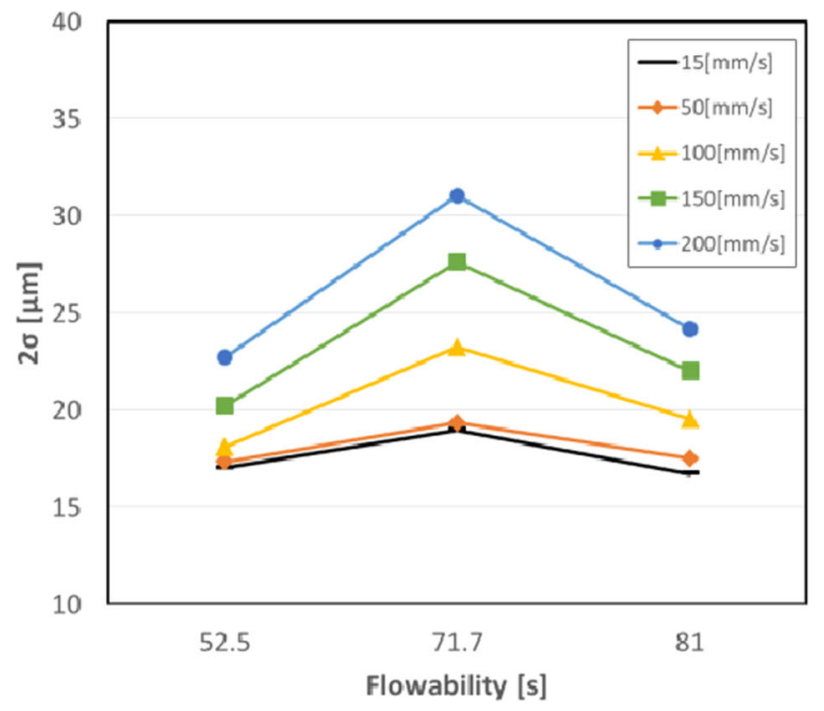

(a)

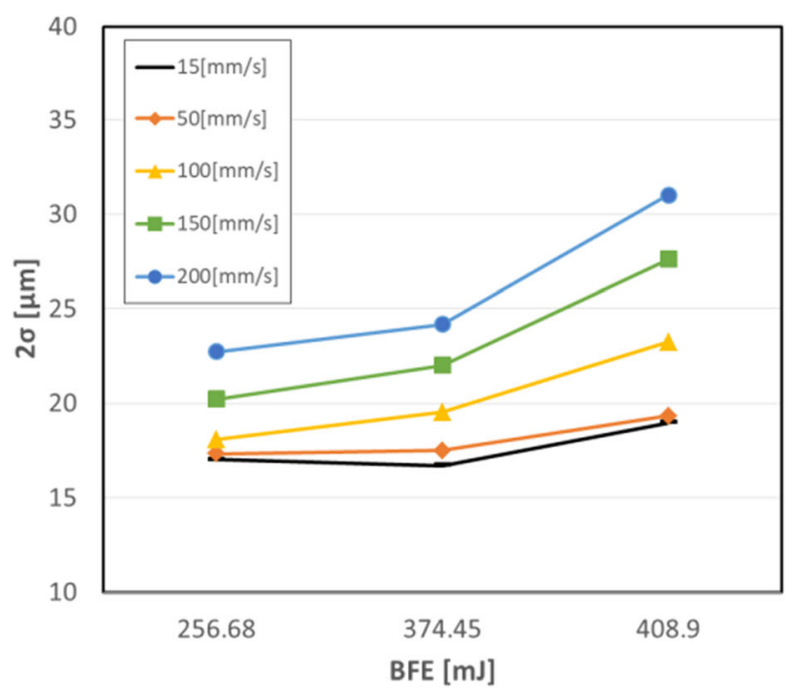

(c) the type of powder. The surface morphology of powder bed is thereby considered to be possible to evaluate using the AOR. This possibility of evaluation using the AOR was also reported by Snow et al. [23]. This suggests that the measurement of the AOR may be utilized for managing the quality of the powder feedstock.

The value of $2 \sigma$ increases with an increase in the BFE because the BFE is related to the cohesiveness of the powder particles. Meier et al. [16] revealed via DEM simulation that decreased particle size (increased cohesiveness) leads to considerably decreased powder layer quality. Therefore, the experimental results of this study may provide evidence for these results obtained via DEM simulation. The trend of the BEF resembles that of the AOR. In addition, because the $\mathrm{SE}$ is identified as the BFE, it is

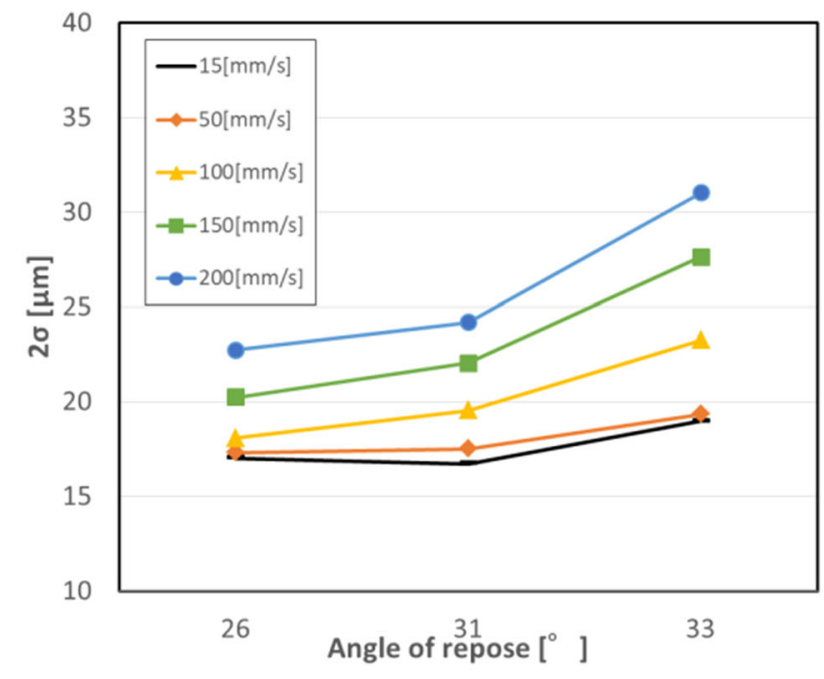

(b)

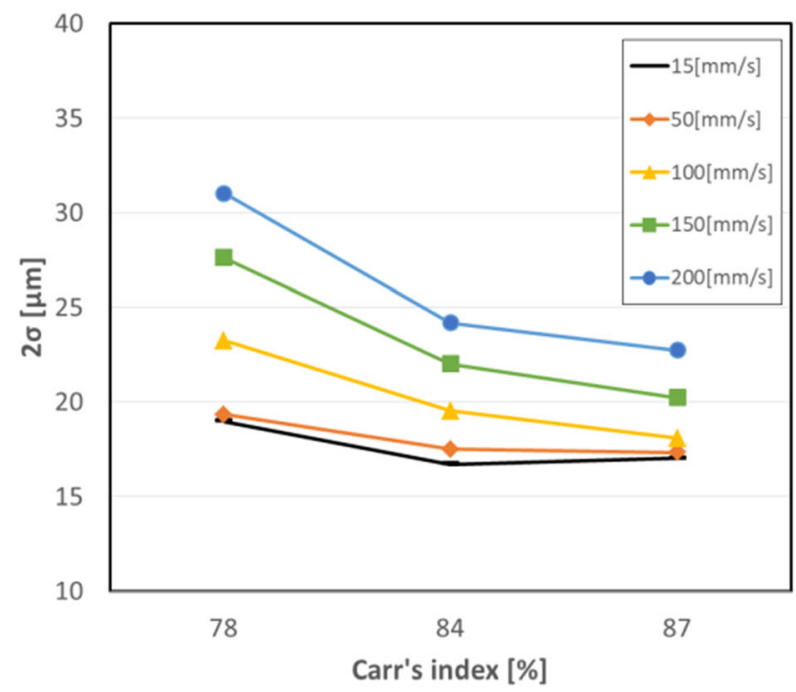

(d)

Fig. 8 Correlation between bulk powder characteristics and surface morphology of the AlSi10Mg powder bed. a Flow rate. b AOR. c BFE. d Carr's index 


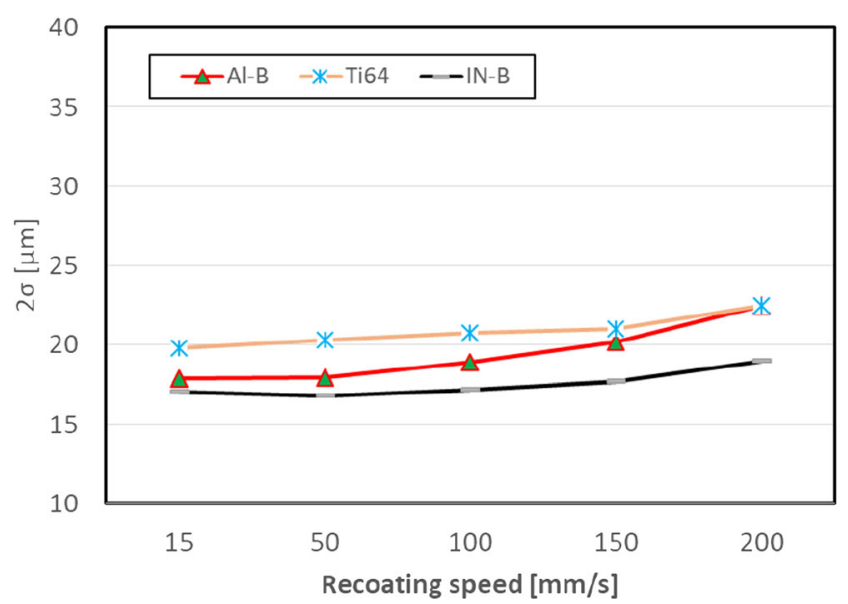

Fig. 9 Variation in the value of $2 \sigma$ for Ti64, Al-B, and IN-B powder beds as a function of the recoating speed

an effective parameter, as reported by Clayton et al. [20]. The value of $2 \sigma$ decreases with an increase in the Carr's index. It is considered that the surface morphology could be improved by increasing the Carr's index because the Carr's index is an indication of the compressibility of a powder.

In addition, the correlation coefficient between the average percentage of increase in $2 \sigma$ and the powder characteristics was analyzed. The correlation coefficient between the average percentage of increase in $2 \sigma$ and the flow rate was around 0.5 , whereas the correlation coefficients between the average percentage of increase in $2 \sigma$ and the AOR, SE, BFE, and Carr's index were more than 0.88 . Thus, the experimental result agrees well with the analyzed one. Consequently, it was found that the surface morphology of the powder bed may be evaluated using the AOR, BFE or SE of the bulk powder.

\subsection{Influence of recoating speed on surface morphology of powder bed}

As noted previously, the surface morphology of the powder bed deteriorates as the recoating speed is increased. To compare with the simulated results reported by Meier et al. [16], the recoating experiment was performed using a spherical gas-atomized Ti64 powder, which is relatively similar to the plasma-atomized Ti64 powder that they employed. The variation in the value of $2 \sigma$ for the Ti64 powder bed including the Al-B and IN-B powder beds as a function of the recoating speed is presented in Fig. 9. The median particle diameter (D50) of the Ti64 powder is $32 \mu \mathrm{m}$, which is approximately similar to the powder used by Meier et al. in their DEM simulation. As shown in Fig. 9, the change in $2 \sigma$ is almost constant with a recoating speed up to $150 \mathrm{~mm} / \mathrm{s}$; thereafter, it tends to increase at $200 \mathrm{~mm} / \mathrm{s}$. According to the standard deviation of the surface morphology simulated by Meir et al. [16], the surface morphology increased significantly at a recoating speed of $100 \mathrm{~mm} / \mathrm{s}$. Although the recoating speed at which the value of $2 \sigma$ increases differs, the increasing tendency is similar to the results of this study. In addition, the value of $2 \sigma$ of these powders increases gradually at a recoating speed of more than $50 \mathrm{~mm} / \mathrm{s}$. This tendency is relatively similar to that obtained by Meir et al. [16]. They stated that this result can partly be attributed not only to the particle agglomerates, but also to particle-to-blade adhesion.

According to the process map created by Desai et al. [17], the surface roughness, $R_{\mathrm{q}}$, is greater than $70 \mu \mathrm{m}$ in the range of 30 to $100 \mathrm{~mm} / \mathrm{s}$. This result is higher than the result of this study. This may be because they used larger powder particles in the range of 100 to $250 \mu \mathrm{m}$.

In addition, it was found that the surface morphology of the spherically shaped powders of Al-B, In-b, and Ti64 is stable at a recoating speed up to $150 \mathrm{~mm} / \mathrm{s}$.

The results of Fig. 6 and Fig. 7 correspond to those obtained in the range of the recoating speed, which is commonly employed in commercial machines. To increase the speed of the process, it is essential to investigate the influence of the recoating speed on the surface morphology of the powder bed at high recoating speeds. Therefore, the recoating test was performed using three types of AlSi10Mg and IN718 powders
Fig. 10 Variation in the surface morphology of the representative AlSi10Mg and IN718 powder beds as a function of recoating speed

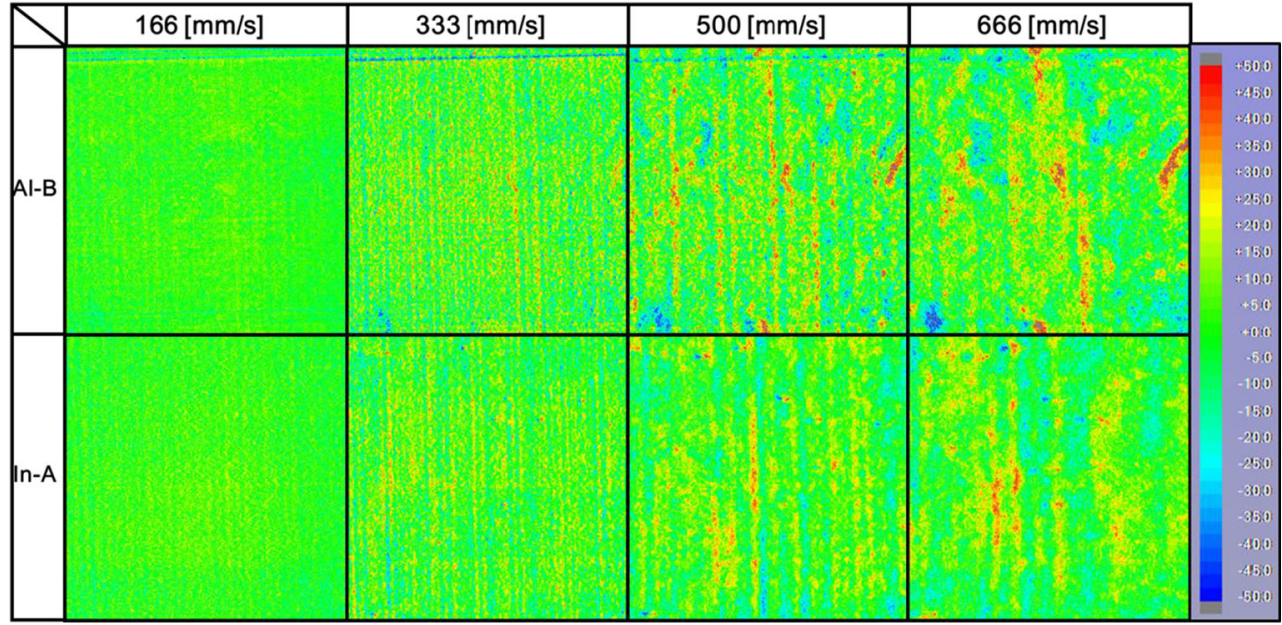




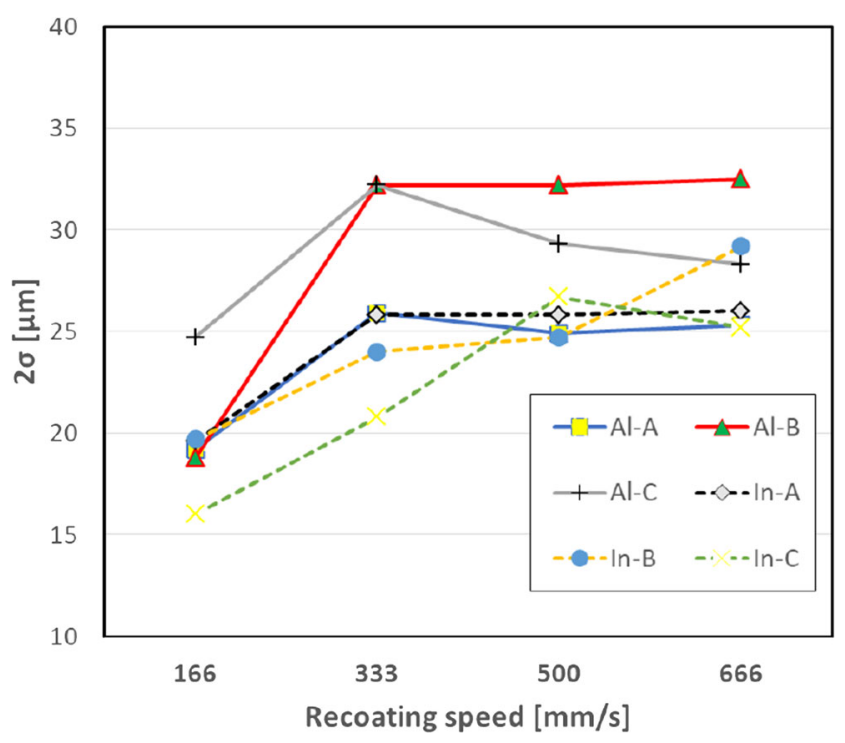

Fig. 11 Variations in the value of $2 \sigma$ for various AlSi10Mg and IN718 powder beds as a function of recoating speed

at a recoating speed of more than $200 \mathrm{~mm} / \mathrm{s}$, which is higher than that of a commercial machine. The variation in the surface morphology of the representative AlSi10Mg and IN718 powder beds as a function of the recoating speed and the variations in the value of $2 \sigma$ for various AlSi10Mg and IN718 powder beds as a function of recoating speed are presented in Fig. 10 and Fig. 11, respectively. The value of $2 \sigma$ increases rapidly as the recoating speed is increased to $333 \mathrm{~mm} / \mathrm{s}$ for all powders. Concerning the AlSi10Mg powder, the values of $2 \sigma$ for $\mathrm{Al}-\mathrm{A}$ and $\mathrm{Al}-\mathrm{B}$ tend to stabilize, whereas that for Al-C tends to decline at a recoating speed of more than 333 $\mathrm{mm} / \mathrm{s}$. Conversely, the value of $2 \sigma$ for IN-A tends to stabilize, whereas that for IN-C increased up to $500 \mathrm{~mm} / \mathrm{s}$ and then stabilized, and that for IN-B increased. Comparing the $2 \sigma$ values of these powder beds at the maximum recoating speed of $667 \mathrm{~mm} / \mathrm{s}$ reveals that IN$\mathrm{C}, \mathrm{Al}-\mathrm{A}$, and IN-A (approximately $20 \mu \mathrm{m}$ ) $<\mathrm{Al}-\mathrm{C}$ and IN-B (approximately $28 \mu \mathrm{m}$ ) < Al-B (approximately 30 $\mu \mathrm{m})$. Therefore, the surface morphology of the AlSi10Mg powder bed will deteriorate more than that of the IN718 powder bed at high recoating speeds. In particular, the AlB powder, which has a spherical shape and shows good flowability, demonstrated an inferior powder bed surface. It may be considered that the AlSi10Mg powder is prone to be blown away (post-flow) more than the IN718 powder at a higher recoating speed because of its lower density. Therefore, the investigation of the surface morphology of the powder bed is required in terms of the acceleration of the recoating speed.

These results indicate that the surface morphology of the powder bed can be quantified using the value of $2 \sigma$. In addition, it was found that the surface morphology of the powder bed is substantially affected by the powder characteristics and recoating speed. The surface morphology of the powder bed for the irregularly shaped powder was more uniform than that for the spherical powder at higher recoating speeds. Moreover, the surface morphology of the powder bed for the latter powder (i.e., a good flowability powder) was more significantly affected than that for the former (i.e., a bad flowability powder) at higher recoating speeds.

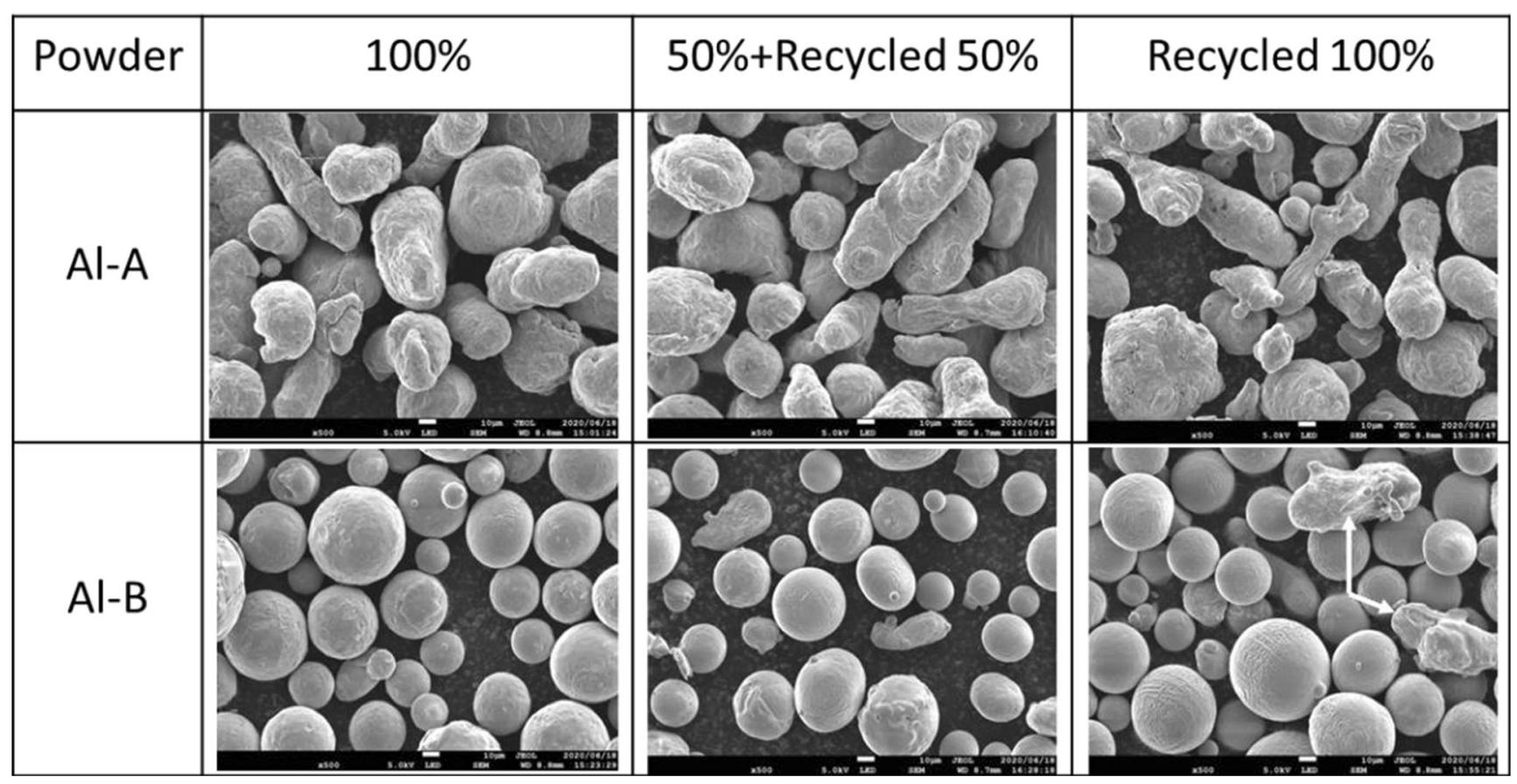

Fig. 12 SEM images of new and recycled AlSi10Mg powders $(\times 500)$ 


\subsection{Influence of recycled powder on surface morphology of powder bed}

The influence of a recycled powder on the surface morphology of the powder bed was investigated using new and recycled Al-A (irregularly shaped) and Al-B (spherical) powders. SEM images of the new and recycled AlSi10Mg powders are presented in Fig. 12. The particle shape of the irregularly shaped Al-A powder drastically changes to a prolonged shape due to friction between the powders resulting from repeated use over a long period. Conversely, the particle shape of the spherical Al-B powder hardly changes, except for some irregularly shaped particles denoted by arrows (Fig. 12). The results of the Hall flow tests are shown in Table 2. The flowability of both the recycled Al-A and Al-B powders deteriorated because the particle shape and surface morphology of the recycled powder were changed by the recycling process. Moreover, the flowability of the spherical Al-B powder is better than that of the irregularly shaped Al-A powder. Strondl et al. [21] reported that recycled EBM powder showed lower flowability than did new EBM powder, whereas recycled SLM powder exhibited better flowability than did the new SLM powder. The results of this study indicate the opposite. This is because they used SLM powder with fine particles, whereas the spherical Al-B powder with a sharppeak PSD was employed in this study.

The variations in the value of $2 \sigma$ for the new and recycled AlSi10Mg powder beds as a function of the recoating speed are shown in Fig. 13. Considering the irregularly shaped Al-A powder, the values of $2 \sigma$ for both the new and recycled powders similarly change with the recoating speed, whereas those of the mixed powders containing 50\% new powder and 50\% recycled powder (Al-AR50 and Al-BR50) are higher than those of the others. Conversely, considering the spherical Al-B powder, the values of $2 \sigma$ for all of these powders change similarly with the recoating speed. Moreover, the value of $2 \sigma$ for Al-A is significantly higher than that of Al-B at higher recoating speeds. Nguyen et al. [22] investigated the flowability of new and recycled IN718 powders using an FT4 powder rheometer. As a result, they reported that the new powder has a relatively good flowability compared with the recycled powder because the new spherical IN718 powder

Table 2 Results of the Hall flow tests of new and recycled AlSi10Mg powders

\begin{tabular}{|c|c|c|c|c|c|}
\hline \multirow[t]{2}{*}{ Powder } & & \multicolumn{2}{|c|}{ Al-A powder } & \multicolumn{2}{|c|}{ Al-B powder } \\
\hline & & New & Recycled & New & Recycled \\
\hline \multirow[t]{2}{*}{ Hall flow test } & $\varphi 5.0 \mathrm{~mm}[\mathrm{~s} / 50 \mathrm{~g}]$ & 12.4 & 16.6 & 8.1 & 11.4 \\
\hline & $\varphi 2.5 \mathrm{~mm}[\mathrm{~s} / 50 \mathrm{~g}]$ & 71.7 & 92.4 & 52.5 & 65.8 \\
\hline
\end{tabular}

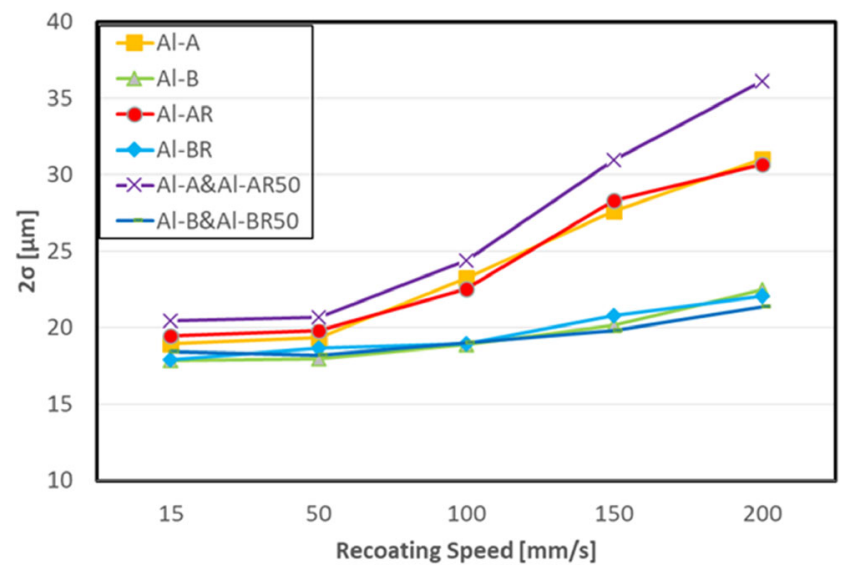

Fig. 13 Variations in the value of $2 \sigma$ for new and recycled AlSi10Mg powder beds as a function of recoating speed

with satellites changed in particle shape via recycling. Their results indicating that the flowability of the recycled powder is lower than that of the new powder are similar to the results of this study.

Therefore, the recycling process deteriorated the flowability of the new powder. However, the surface morphology of the spherical recycled powder was similar to that of the new spherical powder.

\section{Conclusions}

In this study, a surface morphology measurement system composed of a powder recoating test bench and a layer surface morphology measurement apparatus was designed and fabricated. The surface morphology of the powder bed was quantified using this system, and the influences of the powder characteristics and the recoating parameters of the powder supply ratio and recoating speed on the surface morphology were investigated. The following results were obtained:

(1) A surface morphology measurement system was designed and fabricated. The surface morphology of the powder bed was measured using a value of $2 \sigma$ as an indicator of surface roughness.

(2) It was found that the AOR and BFE of the bulk powder are promising parameters for evaluating the surface morphology of a powder bed.

(3) It was found that the surface morphology of the powder bed is significantly affected by the powder characteristics and recoating speed. The value of $2 \sigma$ for the AlSi $10 \mathrm{Mg}$ powder increased gradually over a recoating speed of 50 $\mathrm{mm} / \mathrm{s}$ for all powders. The value of $2 \sigma$ for the irregularly shaped AlSi10Mg powder was approximately $19 \mu \mathrm{m}$, whereas the $2 \sigma$ values for the other powders were approximately $17 \mu \mathrm{m}$ at a recoating speed of $15 \mathrm{~mm} / \mathrm{s}$. However, at a recoating speed of greater than $300 \mathrm{~mm} /$ 
$\mathrm{s}$, the irregularly shaped powder demonstrated a better surface morphology than the spherical powder.

(4) The recycling process deteriorated the flowability of the resulting powders compared with the new powders. However, the surface morphology of the powder bed for the spherical recycled powder was similar to that for the new spherical powder over a recoating speed of $15-200 \mathrm{~mm} / \mathrm{s}$.

Consequently, the correlation among the powder characteristics, recoating conditions, and surface morphology of the powder bed was revealed by employing the surface morphology measurement system. Quantification of the surface morphology of the powder bed using the monitoring system enables control of the recoating process to prevent the occurrence of defects. In this study, however, the influence of the surface morphology of a powder bed on the melting and solidification behavior was not obtained. Therefore, in the future, the influence of the surface morphology of a powder bed on the melting and solidification behavior during laser radiation will be investigated using a new monitoring test bench designed to enable observations of the melt pool behavior and the surface morphologies of a powder bed and a built specimen at a higher resolution. The in situ data will be analyzed using machine learning to improve real-time control of AM process. In addition, the findings of this study are useful for evaluating the surface morphology of a powder bed in binder jetting AM, which is a promising material process for mass production of AM products.

Acknowledgements This paper is based on results obtained from a project commissioned by the Ministry of Economy, Trade, and Industry and the New Energy and Industrial Technology Development Organization (NEDO Project code: P17002). In addition, the authors gratefully acknowledge Toyo Aluminium K.K. for providing powders and powder characteristics data.

Author contribution K.Y., K.T., and H.K. designed the concept of this work. K.Y., M.T., and M.Y. performed the majority of the experiments with assistance from T.I. and H.A. and with advice from all authors. K.Y. and H.K. drafted the manuscript.

Funding The work was supported by the New Energy and Industrial Technology Development Organization (NEDO Project No. P17002).

Data Availability All experimental data are provided in the manuscript.

\section{Declarations}

Conflict of interest The authors declare no competing interests.

Open Access This article is licensed under a Creative Commons Attribution 4.0 International License, which permits use, sharing, adaptation, distribution and reproduction in any medium or format, as long as you give appropriate credit to the original author(s) and the source, provide a link to the Creative Commons licence, and indicate if changes were made. The images or other third party material in this article are included in the article's Creative Commons licence, unless indicated otherwise in a credit line to the material. If material is not included in the article's Creative Commons licence and your intended use is not permitted by statutory regulation or exceeds the permitted use, you will need to obtain permission directly from the copyright holder. To view a copy of this licence, visit http://creativecommons.org/licenses/by/4.0/.

\section{References}

1. Everton SK, Hirsch M, Stravroulakis P, Leach RK, Clare AT (2016) Review of in-situ process monitoring and in-situ metrology for metal additive manufacturing. Mater Des 95:431-445

2. Mani M, Lane BM, Donmez MA, Feng SC, Moylan SP, Fesperman RR Jr (2015) Measurement science needs for real-time control of additive manufacturing powder bed fusion processes. Int J Prod Res. https://doi.org/10.6028/NIST.IR.8036

3. Moges T, Ameta G, Witherell P (2019) A review of model inaccuracy and parameter uncertainty in laser powder bed fusion models and simulation. J Manuf Sci Eng 141:040801

4. Mindt HW, Megahed M, Lavery NP, Holmes MA, Brown SGR (2016) Powder bed layer characteristics: the overseen first-order process input. Metal Mat Trans A 47A:3811-3822

5. Spierings AB, Herres N, Levy G (2010) Influence of the particle size distribution on surface quality and mechanical properties in additive manufactured stainless steel parts. Rapid Prototyp J 17: 195-202

6. Spierings AB, Levy G (2009) Comparison of density of stainless steel 316L parts produced with selective laser melting using different powder grades. Proc SFF Symposium 342-353

7. King WE, Anderson AT, Ferencz RM, Hodge NE, Kamath C, Khairallah SA, Rubenchik AM (2015) Laser powder bed fusion additive manufacturing of metals; physics, computational, and materials challenges. Appl Phys Rev 2:041304

8. Tan JH, LW WW, Dalgarno KW (2017) An overview of powder granulometry on feedstock and part performance in the selective laser melting process. Addit Manuf 18:228-255

9. Vock S, Klöden B, Kirchner A, Weißgärber T, Kieback B (2019) Powders for powder bed fusion: a review. Prog Addit Manuf 4: 383-397

10. Haeri S, Wang Y, Ghita O, Su J (2016) Discrete element simulation and experimental study of powder spreading process in additive manufacturing. Powder Technol 306:45-54

11. Parteli EJR (2013) DEM simulation of particles of complex shapes using the multisphere method: application for additive manufacturing. AIP Conf Proc 1542:185. https://doi.org/10.1063/1.4811898

12. Parteli EJR, Pöschel T (2016) Particle-based simulation of powder application in additive manufacturing. Powder Technol 288:96102

13. Xiang Z, Yin M, Deng Z, Mei X, Yin G (2016) Simulation of forming process of powder bed for additive manufacturing. $J$ Manuf Sci Eng 138:081002-081001

14. Haeri S (2017) Optimisation of blade type spreaders for powder bed preparation in additive manufacturing using DEM simulations. Powder Technol 321:94-104

15. Herbold EB, Walton O, Homel MA (2015) Simulation of powder layer deposition in additive manufacturing processes using the discrete element method, LLNL-TR-678550 October 26 
16. Meier C, Weissbach Weinberg RJ, Wallb WA, Hart AJ (2019) Critical influences of particle size and adhesion on the powder layer uniformity in metal additive manufacturing. J Mater Process Technol 266:484-501

17. Desai PS, Higgs CF III (2019) Spreading process maps for powderbed additive manufacturing derived from physics model-based machine learning. Metals 9:1176. https://doi.org/10.3390/met9111176

18. Steuben JC, Iliopoulos AP, Michopoulos JG (2016) Discrete element modeling of particle-based additive manufacturing processes. Comput Methods Appl Mech Eng 305:537-561

19. Spierings AB, Voegtlin M, Bauer T, Wegene K (2015) Powder flowability characterisation methodology for powder-bed-based metal additive manufacturing. Prog Addit Manuf 1:9-20

20. Clayton J, Millington-Smith D, Armstrong B (2015) The application of powder rheology in additive manufacturing. JOM 67:544 548

21. Strondl A, Lyckfeldt O, Brodin H, Ackelid U (2015) Characterization and control of powder properties for additive manufacturing. JOM 67:540-554

22. Nguyen QB, Ling M, Nai S, Zhu Z, Sun C-N, Wei J, Zhou W (2017) Characteristics of Inconel powders for powder-bed additive manufacturing. Engineering 3:695-700

23. Snow Z, Martukanitz R, Joshi RS (2019) On the development of powder spreadability metrics and feedstock requirements for powder bed fusion additive manufacturing. Addit Manuf 28:78-86

24. Amado A, Schmidt M, Levy G, Wegner K (2011) Advances in SLS powder characterization. Proc SFF Symposium 2011:438-452

25. Karapatis NP, Egger G, Gygax P-E, Glardon R (1999) Optimization of powder layer density in selective laser sintering. Proc SFF symposium 1999:255-263

26. Jacob G, Donmez A, Slotwinski J, Moylan S (2016) Measurement of powder bed density in powder bed fusion additive manufacturing processes. Meas Sci Technol 27:115601

27. Ali U, Mahmoodkhani Y, Shahabad SI, Esmaeilizadeh R, Liravi F, Sheydaeian E, Huang KY, Marzbanrad E, Vlasea M, Toyserkani E (2018) On the measurement of relative powder-bed compaction density in powder-bed additive manufacturing processes. Mater Des 155:495-501

28. King WE, Anderson T, FerenczRM HNE, Kamath C, Khairallah SA (2015) Overview of modelling and simulation of metal powder bed fusion process at Lawrence Livermore National Laboratory. Mater Sci Technol 31:957-968

29. Qiu C, Panwisawas C, Ward W, Basoalto HC, Brooks JW (2015) On the role of melt flow into the surface structure and porosity development during selective laser melting. Acta Mater 96:72-79

30. Khairallah SA, Anderson AT, Rubenchik AM, King WE (2016) Laser powder-bed fusion additive manufacturing: physics of complex melt flow and formation mechanisms of pores, spatter, and denudation zones. Acta Mater 108:36-45

31. Matthews MJ, Guss G, Khairallah SA, Rubenchik AM, Depond PJ, King WE (2016) Denudation of metal powder layers in laser powder bed fusion processes. Acta Mater 114:33-42

32. Martin AA, Calta NP, Khairallah SA, Wang J, Depond PJ, Fong AY, Thampy V, Guss GM, Kiss AM, Stone KH, Tassone CJ, Weker JN, Toney MF, Van Buurenl T, Matthews MJ (2019) Dynamics of pore formation during laser powder bed fusion additive manufacturing. Nature Comm 10:1987. https://doi.org/10. 1038/s41467-019-10009-2

33. Cunningham R, Zhao C, Parab N, Kantzos C, Pauza J, Fezzaa K, Sun T, Rollett AD (2019) Keyhole threshold and morphology in laser melting revealed by ultrahigh-speed x-ray imaging. Science 363:849-852
34. Kyogoku H, Ikeshoji T-T (2020) A review of metal additive manufacturing technologies: mechanism of defects formation and simulation of melting and solidification phenomena in laser powder bed fusion process. Mech Eng Rev 7:19-00182

35. Bourell D, Kruth JP, Leu M, Levy G, Rosen D, Beese AM, Clare A (2017) Materials for additive manufacturing. CIRP Annals - Manuf Technol 66:659-681

36. DebRoy T, Wei HL, Zuback JS, Mukherjee T, Elmer JW, Milewski JO, Beese AM, Wilson-Heid A, Ded A, Zhang W (2018) Additive manufacturing of metallic components - process, structure and properties. Prog Mater Sci 92:112-224

37. Mindt H-W, Desmaison O, Megahed M, Peralta A, Neumann J (2018) Modeling of powder bed manufacturing defects. J Mater Eng Perform 27:32-43

38. Hebert RJ (2016) Viewpoint: metallurgical aspects of powder bed metal additive manufacturing. J Mater Sci 5:11165-11175

39. Wu Y-C, San C-H, Chang C-H, Lin H-J, Marwan R, Baba S, Hwang WS (2018) Numerical modeling of melt-pool behavior in selective laser melting with random powder distribution and experimental validation. J Mater Process Technol 254:72-78

40. Jacob G, Brown CU, Donmez A (2018) The influence of spreading metal powders with different particle size distributions on the powder bed density in laser-based powder bed fusion processes, NIST Advanced Manufacturing Series 100-17 March

41. Sun YY, Gulizia S, Oh CH, Doblin C, Yang YF, Qian M (2015) Manipulation and characterization of a novel titanium powder precursor for additive manufacturing applications. JOM 67:564-572

42. DePond PJ, Guss G, Ly S, Calta NP, Deane D, Khairallah S, Matthews MJ (2018) In situ measurements of layer roughness during laser powder bed fusion additive manufacturing using low coherence scanning interferometry. Mater Design 154:347-359

43. Zhang B, Ziegert J, Farahi F, Davies A (2016) In situ surface topography of laser powder bed fusion using fringe projection. Addit Manuf 12:100-107

44. Kalms M, Narita R, Thomy C, Vollertsen F, Bergmann RB (2019) New approach to evaluate 3D laser printed parts in powder bed fusion-based additive manufacturing in-line within closed space. Addit Manuf 26:161-165

45. Liu Y, Blunt L, Zhang Z, Rahman HA, Gao F, Jiang X (2020) Insitu areal inspection of powder bed for electron beam fusion system based on fringe projection profilometry. Addit Manuf 31:100940

46. Geldart D, Abdullah EC, Hassanpour A, Nwoke LC, Wouters I (2006) Characterization of powder flowability using measurement of angle of repose. China Particuology 4:104-107

47. Coe HG, Pasebani S (2020) Use of bimodal particle size distribution in selective laser melting of $316 \mathrm{~L}$ stainless steel. J Manuf Mater Process 4:8. https://doi.org/10.3390/jmmp4010008

48. Freeman Technology (2020) Shear Testing. https://www. freemantech.co.uk/powder-testing/ft4-powder-rheometer-powderflow-tester/shear-testing (accessed 28 September)

49. James WB (2019) ASTM committee B09 workshop on powder characterization. Int J Powder Met 55:44-55

50. Chen H, Chen Y, Liu Y, Wei Q, Shi Y, Yan W (2020) Packing quality of powder layer during counter-rolling-type powder spreading process in additive manufacturing. Int $\mathbf{J}$ Mach Tools Manuf $153: 103553$

Publisher's note Springer Nature remains neutral with regard to jurisdictional claims in published maps and institutional affiliations. 